\title{
Caracterização funcional dos casos de doença de Huntington em um município
}

\section{brasileiro}

Functional characterization of Huntington's disease cases in a brazilian municipality

Caracterización funcional de los casos de enfermedad de Huntington en un municipio brasileño

Recebido: 31/05/2021 | Revisado: 13/06/2021 | Aceito: 18/06/2021 | Publicado: 02/07/2021

João Vitor Santana Santos

ORCID: https://orcid.org/0000-0002-5011-356X Prefeitura de Inhapi, Brasil

E-mail: joaovictor2200914@gmail.com

João Ancelmo dos Reis Neto

ORCID: https://orcid.org/0000-0002-1363-5967 Hospital São Camilo, Brasil

E-mail: jneto1995@hotmail.com

Nívea Carla dos Reis Silva do Amorim

ORCID: https://orcid.org/0000-0003-2638-616X Centro Universitário CESMAC, Brasil

E-mail: niveacarla@hotmail.com

Kamilla Peixoto Bandeira

ORCID: https://orcid.org/0000-0002-0429-0530 Centro de triagem para COVID-19 de Rio Largo, Brasil

E-mail: kamilla.peixoto@hotmail.com

Monique Carla da Silva Reis

ORCID: https://orcid.org/0000-0002-8815-3938

Universidade Estadual de Ciências da Saúde de Alagoas, Brasil

E-mail: moniquecsto@gmail.com

\section{Resumo}

A Doença de Huntington (DH) é uma desordem neurodegenerativa de herança autossômica dominante. Os sintomas se caracterizam por uma tríade, distúrbio dos movimentos, mudanças de humor e comprometimento cognitivo. Tratase de um estudo transversal, descritivo, com objetivo de identificar o estado funcional dos pacientes com DH, a partir de uma amostra censitária, analisando todos os pacientes diagnosticados no município. A pesquisa foi realizada em um município alagoano, com vinte indivíduos diagnosticados com a doença. Para alcançar os objetivos, foi utilizado um questionário validado para a população brasileira, a Medida de Independência Funcional (MIF), o qual identifica a dependência de uma pessoa referente a sua capacidade funcional, avaliando a dificuldade nas realizações de tarefas do autocuidado, mobilidade e comunicação. A partir da análise dos resultados foi possível identificar as relações de parentesco existentes, o tipo de assistência médica e de reabilitação que cada participante está submetido e a sua condição funcional, levando os pesquisadores a caracterizar cada um deles e concluir que a limitação no acesso a serviços especializados em reabilitação física e a ausência de aconselhamento genético leva à continuidade dos casos e à alta prevalência dessa patologia no município.

Palavras-chave: Doença de Huntington; Epidemiologia; Capacidade funcional.

\begin{abstract}
Huntington's disease (HD) is a neurodegenerative disorder of autosomal dominant inheritance. The symptoms are characterized by a triad, movement disorder, mood changes, and cognitive impairment. This is a cross-sectional, descriptive study, aiming to identify the functional status of HD patients, from a census sample, analyzing all patients diagnosed in the municipality. The research was carried out in a city of Alagoas, with twenty individuals diagnosed with the disease. To achieve the objectives, we used a questionnaire validated for the Brazilian population, the Functional Independence Measure (FIM), which identifies the dependence of a person on their functional capacity, assessing the difficulty in performing self-care tasks, mobility and communication. From the analysis of the results it was possible to identify the existing family relationships, the type of medical and rehabilitation assistance that each participant is submitted to, and their functional condition, leading the researchers to characterize each of them and conclude that the limitation in access to specialized services in physical rehabilitation and the absence of genetic counseling leads to the continuity of cases and the high prevalence of this pathology in the city.
\end{abstract}

Keywords: Huntington's disease; Epidemiology; Functional capacity. 


\begin{abstract}
Resumen
La enfermedad de Huntington $(\mathrm{EH})$ es un trastorno neurodegenerativo de herencia autosómica dominante. Los síntomas se caracterizan por una tríada, trastorno del movimiento, cambios de humor y deterioro cognitivo. Se trata de un estudio transversal y descriptivo, cuyo objetivo es identificar el estado funcional de los pacientes con EH, a partir de una muestra censal, analizando todos los pacientes diagnosticados en el municipio. La investigación se realizó en un municipio de Alagoas, con veinte individuos diagnosticados con la enfermedad. Para alcanzar los objetivos, se utilizó un cuestionario validado para la población brasileña, el Functional Independence Measure (FIM), que identifica la dependencia de una persona en relación con su capacidad funcional, evaluando la dificultad para realizar tareas de autocuidado, movilidad y comunicación. A partir del análisis de los resultados fue posible identificar las relaciones de parentesco existentes, el tipo de asistencia médica y de rehabilitación a la que se somete cada participante y su condición funcional, lo que llevó a los investigadores a caracterizar a cada uno de ellos y a concluir que la limitación en el acceso a los servicios especializados en rehabilitación física y la ausencia de asesoramiento genético conlleva la continuidad de los casos y la alta prevalencia de esta patología en el municipio.
\end{abstract}

Palabras clave: Enfermedad de Huntington; Epidemíology; Capacidad funcional.

\title{
1. Introdução
}

A Doença de Huntington (DH) foi descoberta em 1872 pelo médico americano George Huntington, mas somente em 1993 a sua causa foi identificada. George Huntington descreveu a doença como coreia hereditária observando que as características clínicas eram associadas a manifestações psiquiátricas e cognitivas, cujo início se dava na fase adulta e tendo, principalmente, um caráter hereditário, com transmissão autossômica dominante (Martelli, 2014).

Sua etiologia é reconhecida como um defeito genético pelo aumento da repetição do códão CAG (citosinaadenosina-guanina) do gene IT 15 especificamente no braço curto do cromossomo quatro, que ocasiona a degeneração gradual do sistema nervoso (Intrieri et al., 2015). Tem início insidioso, em torno dos 40 a 50 anos de idade e tem piora gradual, podendo levar à morte em 10 a 20 anos.

Os sintomas da doença comumente se iniciam a partir de leves abalos dos músculos da face, que aumentam gradativamente em intensidade e variedade. As pálpebras são mantidas piscando, a testa franzida e depois elevada, o nariz torcido para um lado, seguido pelo outro lado e a boca se volta em direções variadas (Huntington, 1872 apud Intrieri et al., 2015).

O diagnóstico da DH pode ser obtido através de um conjunto de elementos, como histórico familiar detalhado, exames de neuroimagem, observação clínica dos sintomas como os déficits motores progressivos e associados à coreia, bem como a partir da realização de teste genético que identifica o número das repetições de CAG (Intrieri et al., 2015).

Estimativas mundiais calculam a prevalência de DH numa média de 2,7 a cada 100.000 pessoas, sendo que em regiões como a América do Norte, Europa e Austrália, esta média sobe para 5,7 a cada 100.000 pessoas. De acordo com a American Psychological Association - APA (2014), a incidência da DH é menor (cerca de 0,40 a cada 100.000 pessoas) na Ásia. A Alemanha registra uma incidência de aproximadamente 10.000 pessoas com DH e outras 50.000 no risco de desenvolverem porque um dos genitores tem/tiveram; já nos EUA estima-se que 30.000 pessoas têm DH e outras 150.000 pertençam ao grupo de risco (Associação Brasil Huntington, 2016).

No Brasil ainda não existem estatísticas oficiais quanto ao número de casos da Doença de Huntington, embora se estima que haja entre 13.000 a 19.000 pessoas com o gene e outras 65.000 a 95.000 no grupo de risco (Associação Brasil Huntington, 2016). Os únicos dados gerais disponíveis atualmente sobre a DH no Brasil concentram-se nos registros da Associação Brasil Huntington (ABH) que, de acordo com quantitativos do ano de 2017, apresenta um total de 2.481 famílias cadastradas. Há ainda registros de três principais aglomerados populacionais (também denominados clusters de DH) com alta incidência de casos: na cidade de Feira Grande, no estado de Alagoas; na cidade de Sobral, no Ceará; e na cidade de Ervália, em Minas Gerais (Associação Brasil Huntington, 2016). 
Dessas regiões apenas dois estados possuem na literatura dados estatísticos, Feira Grande no estado de Alagoas, possui uma prevalência de 10,4/10.000 habitantes; e em Ervália no estado de Minas Gerais, a prevalência é de 7,2/10.000 habitantes. Tal limitação de informações fidedignas sobre a DH, indica a escassez de diagnósticos da doença no país (Alencar et al., 2010).

Na cidade de Feira Grande são descritos casos da DH desde 2010. Localizada no Agreste alagoano, possui população estimada em 22.481 pessoas (IBGE, 2017). O município chegou a apresentar, no ano de 2010, 22 casos resultantes da consanguinidade, isto é, pessoas nascidas de casais que apresentam graus de parentesco, sendo elevado à categoria de município com maior prevalência da DH no Brasil (Alencar et al., 2010).

A confirmação do diagnóstico de DH representa uma perda progressiva de autonomia e independência, onde a pessoa tem as suas capacidades físicas, cognitivas e psiquiátricas afetadas e declinam até a demência (Associação Brasil Huntington, 2016), sendo necessário conhecer como se dá o processo de evolução da doença, por isso, o objetivo desse estudo foi identificar o grau capacidade funcional de pessoas portadoras da $\mathrm{DH}$, em um município alagoano.

\section{Metodologia}

Trata-se da descrição de uma série de casos, desenvolvida no município de Feira Grande, no estado de Alagoas, situado no nordeste brasileiro. A amostra foi censitária, sendo incluídos todos os pacientes diagnosticados no município a partir de um cadastro existente na Secretaria Municipal de Saúde.

O estudo seguiu os critérios éticos conforme a resolução 466/12 e teve parecer favorável através da Plataforma Brasil, vinculada ao Comitê de Ética em Pesquisa (CEP) da Universidade Estadual de Ciências da Saúde de Alagoas (UNCISAL), número 13609119.7.0000.5011. Após aprovação no CEP, iniciou-se a coleta de informações na Secretaria Municipal de Saúde, onde foi construído um mapa territorial para localização dos pacientes na área urbana e rural. Em seguida, foi realizado contato individual e o convite para participar da pesquisa, na ocasião, foram apresentados os instrumentos de coleta de dados e o Termo de Consentimento Livre e Esclarecido (TCLE), com as explicações necessárias para confirmação e participação voluntária no estudo. Os autores afirmam não ter recebido qualquer forma de financiamento para a execução deste estudo.

Para alcançar os resultados, os autores construíram um questionário sociodemográfico com o objetivo de traçar o perfil da amostra, incluindo quinze itens, como, identificação, sexo, irmãos, filhos, filhas, data de avaliação, data de nascimento, entrevistado, parentes com a doença, quando iniciaram os sintomas, faz tratamento, quais, local de tratamento e recebeu alguma informação da transmissão genética.

Para atender ao objetivo principal, foi utilizada a Medida de Independência Funcional (MIF) para identificar a capacidade funcional dos participantes da pesquisa. A MIF é um instrumento que avalia 18 categorias pontuando de 1 (um) a 7 (sete) e classificando-as quanto ao nível de independência para a realização da tarefa. As categorias são agrupadas em seis dimensões: 1 - Autocuidados (alimentação, higiene pessoal, banho, vestir metade superior, vestir metade inferior, utilização do vaso sanitário); 2 - Controles de esfíncteres (controle da diurese e defecação); 3 - Transferências (leito, cadeira, cadeira de rodas, vaso sanitário, banheiro, chuveiro); 4 - Locomoções (marcha, cadeira de rodas, escadas); 5 - Comunicações (compreensão, expressão); 6 - Cognições sociais (interação social, resolução de problemas, memória) (Riberto, Miyazaki \& Jucá, 2004).

Os dados foram analisados utilizando o software Bioestat versão 5.3, em que as variáveis foram descritas por frequências absoluta. 


\section{Resultados}

A coleta de dados aconteceu entre os meses de setembro e outubro de 2020, onde vinte voluntários, diagnosticados com a doença de Huntington participaram do estudo, sem perda amostral, visto que não houve renúncia, óbito ou desistência durante esse período. Todos os participantes são residentes no município de Feira Grande, localizado no agreste de Alagoas. Do total da amostra, doze participantes da pesquisa (60\%) eram do sexo masculino e oito (40\%) eram do sexo feminino, sendo nove $(45 \%)$ residentes na zona urbana e onze (55\%) na zona rural do município. As características sociodemográficas estão descritas na Tabela 1.

Tabela 1. Características sociodemográficas dos participantes da pesquisa.

\begin{tabular}{|c|c|c|}
\hline $\begin{array}{l}\text { Participante } \\
\text { da pesquisa }\end{array}$ & $\begin{array}{l}\text { Idade } \\
\text { (anos) }\end{array}$ & Sexo \\
\hline A1 & 49 & Feminino \\
\hline A2 & 47 & Feminino \\
\hline B1 & 58 & Masculino \\
\hline B2 & 58 & Masculino \\
\hline B3 & 61 & Masculino \\
\hline B4 & 68 & Masculino \\
\hline B5 & 58 & Masculino \\
\hline B6 & 52 & Masculino \\
\hline C1 & 33 & Masculino \\
\hline $\mathrm{C2}$ & 36 & Masculino \\
\hline C3 & 52 & Feminino \\
\hline D1 & 44 & Masculino \\
\hline D2 & 50 & Feminino \\
\hline D3 & 72 & Feminino \\
\hline D4 & 71 & Feminino \\
\hline E1 & 49 & Feminino \\
\hline $\mathbf{E 2}$ & 50 & Masculino \\
\hline F1 & 71 & Feminino \\
\hline F2 & 38 & Masculino \\
\hline G1 & 48 & Masculino \\
\hline
\end{tabular}

Fonte: Autores.

Os resultados sobre a relação de parentesco, capacidade funcional e tratamento ao qual cada um dos participantes da pesquisa citou ser submetidos, foram organizados por grupos familiares, para melhor compreensão.

As participantes da pesquisa A1 (49 anos) e A2 (47 anos), são irmãs, residem na área urbana, têm a transmissão genética da mãe, que faleceu devido à doença. A1 apresentou os sintomas da doença aos 35 anos e tem uma filha de 23 anos, que não apresenta sintomas. Enquanto A2 iniciou os sintomas aos 40 anos de idade e não tem filhos. As duas fazem 
tratamento no Centro de Atenção Psicossocial (CAPS) do município e na Unidade Básica de Saúde (UBS) fazem uso de medicamentos para o controle dos movimentos involuntários e para regular o sono.

Os irmãos B1 (58 anos), B2 (58 anos), B3 (61 anos) e B4 (68 anos) têm a transmissão genética do pai. Os irmãos B1 e B2 são gêmeos, ambos têm filhos e apresentaram os sintomas aos 40 anos de idade, estão acamados e assistidos em seus domicílios pela equipe da unidade de saúde do território e pelo CAPS. Os irmãos B3 e B4 apresentaram os sintomas aos 45 anos de idade, têm filhos e fazem tratamento psiquiátrico no CAPS e na unidade de saúde do território. Eles são primos de primeiro grau de B5 (58 anos) e B6 (52 anos), a família não soube precisar exatamente quando começaram os sintomas da doença do primeiro deles, mas relata que está na fase inicial. Assim como os demais, faz tratamento no CAPS e tem filhos. Já B6 (52 anos) está acamado, também tem filhos, apresentou os sintomas aos 47 anos, faz tratamento no domicílio através da assistência prestada pela unidade de saúde do território e pelo CAPS.

Em outras famílias os sintomas apareceram mais cedo, como é o caso de C1 (33 anos), C2 (36 anos) e C3 (52 anos), são irmãos, têm a transmissão genética do pai e residem na área urbana. C1 iniciou os sintomas aos 19 anos e C2 aos 33 anos de idade e se encontram acamados. Ambos não têm filhos e fazem tratamento na unidade de saúde e no CAPS. O terceiro, C3 apresentou os sintomas aos 46 anos de idade, tem filhos, não faz tratamento de reabilitação, faz uso de medicamentos para controlar os movimentos involuntários.

Os irmãos D1 (44 anos), D2 (50 anos) e D3 (71 anos), tiveram a transmissão genética tanto do pai, quanto da mãe, ambos faleceram em decorrência das complicações causadas pela doença. Os irmãos residem na área rural, o mais novo (D1) iniciou os sintomas há um ano, tem filhos, não faz tratamento de reabilitação, faz uso de medicamentos para controlar os movimentos involuntários. D2 iniciou os sintomas aos 46 anos, tem filhos, faz acompanhamento psiquiátrico e uso de medicamentos para controlar os movimentos involuntários. D3 iniciou a apresentação dos sintomas aos 67 anos (idosa), tem filhos, está acamada há dois anos, faz tratamento de reabilitação na Associação de Pais e Amigos dos Excepcionais (APAE), com fisioterapeuta, fonoaudiólogo e terapeuta ocupacional, além de fazer uso de medicamentos para controlar os movimentos involuntários. Eles são primos de primeiro grau de D4 (71 anos), que tem a transmissão genética da mãe, tem filhos, acamada há 23 anos, reside na área urbana, apresentou os sintomas aos 46 anos, não faz tratamento de reabilitação, faz uso de medicamento para controlar os movimentos involuntários e para dormir.

A família dos irmãos E1 (49 anos) e E2 (50 anos) tem transmissão genética do pai, que faleceu em decorrência da doença. Os irmãos residem na área urbana, não fazem tratamento de reabilitação e são acompanhados pela equipe da unidade de saúde do território. Os sintomas de E1 tiveram início aos 40 anos, a participante da pesquisa tem filhos e faz uso de medicamentos para controlar os movimentos involuntários. Seu irmão E2 iniciou os sintomas na mesma idade e está acamado há um ano e meio, ele tem filhos e faz uso de medicamentos para controlar os movimentos involuntários e para dormir.

F1 (71 anos) reside na área rural do município, tem a transmissão genética do pai, tem filhos, iniciou os sintomas aos 61 anos, faz tratamento no CAPS e uso de medicamentos para controlar os movimentos involuntários. Tia de F2 (38 anos), que é residente da área rural do município, também relata que a transmissão genética veio do pai, não tem filhos, iniciou os sintomas aos 23 anos e há dez anos está acamado, não faz tratamento específico e é acompanhado pela equipe da unidade de saúde do território e recebe assistência do médico psiquiatra do CAPS.

G1 (48 anos) reside na área rural do município, tem a transmissão genética do pai, iniciou os sintomas aos 38 anos de idade. Está acamado há dois anos, faz uso de medicamento para controlar os movimentos involuntários e faz tratamento no CAPS. 
Quanto aos resultados da investigação da capacidade funcional, o Gráfico 1 descreve os domínios avaliados através da MIF, obtidos por meio de entrevista com o participante da pesquisa ou com o seu cuidador e observou os níveis de comprometimento funcional deles.

Considerando-se a classificação dos participantes, na família das irmãs A1(49 anos) e A2 (47 anos), existe independência modificada, com necessidade de auxílio para executar as atividades. Os irmãos B1 (58 anos), B2 (58 anos), B4 (68 anos) e B6 (52 anos) apresentam dependência total nas habilidades funcionais, passando maior parte do dia no leito. B3 (61 anos) e B5 (58 anos) apresentam perdas das habilidades funcionais, precisando de assistência moderada.

Enquanto C1 (33 anos) apresenta independência das habilidades funcionais, conseguindo realizar as atividades previstas no instrumento de pesquisa e C2 (36 anos) tem dependência completa das habilidades funcionais, permanecendo maior parte do dia no leito. A irmã mais velha, C3 (52 anos), apresenta perdas das habilidades funcionais, necessitando de assistência moderada.

D1 (44 anos) apresentou resultados que indicam independência completa, não necessitando de ajuda para desenvolver as tarefas descritas. D2 (50 anos) possui perdas das habilidades funcionais, necessitando de auxílio moderado, precisando de ajuda de terceiros para executar algumas atividades nos cuidados pessoais e transferência. D3 (72 anos) e D4 (71 anos) apresentam perdas totais das habilidades funcionais, necessitando de assistência máxima.

Entre os irmãos E1 e E2, o primeiro, E1 (49 anos) apresenta dependência completa nas tarefas de cuidados pessoais e dependência moderada nos demais itens, requer supervisão de terceiros para desenvolver as atividades, enquanto E2 (50 anos) necessita de assistência total, pois apresentou perdas funcionais que o impede de realizar as tarefas.

Já na família de F1 (38 anos) e F2 (71 anos), o primeiro apresenta perdas totais das habilidades funcionais investigadas, demandando a assistência de terceiros, e F2 (71 anos) apresenta dependência completa nas habilidades dos cuidados pessoais e no controle de esfíncteres, e assistência moderada nos outros itens de avaliação.

G1 (48 anos) apresenta dependência completa das habilidades funcionais, precisando de assistência total para executar as tarefas investigadas.

Os participantes da pesquisa estão distribuídos nos três estágios da doença, onde dois deles (10\%) se encontram no primeiro estágio; oito (40\%) no segundo estágio e dez (50\%) no terceiro estágio da doença. Quanto ao grupo de dependências, dezoito (90\%) deles são dependentes e dois (10\%) foram caracterizados como independentes, conforme a classificação de funcionalidade do instrumento de investigação. Entre os participantes da pesquisa caracterizados como dependentes, dois (10\%) necessitam apenas de auxílio; dez (50\%) têm necessidade de assistência total; quatro (20\%) assistência moderada e dois (10\%) têm necessidade de supervisão, para realizar as atividades investigadas através da MIF. 
Gráfico 1. Caracterização da capacidade funcional dos portadores de Huntington avaliado pela MIF.

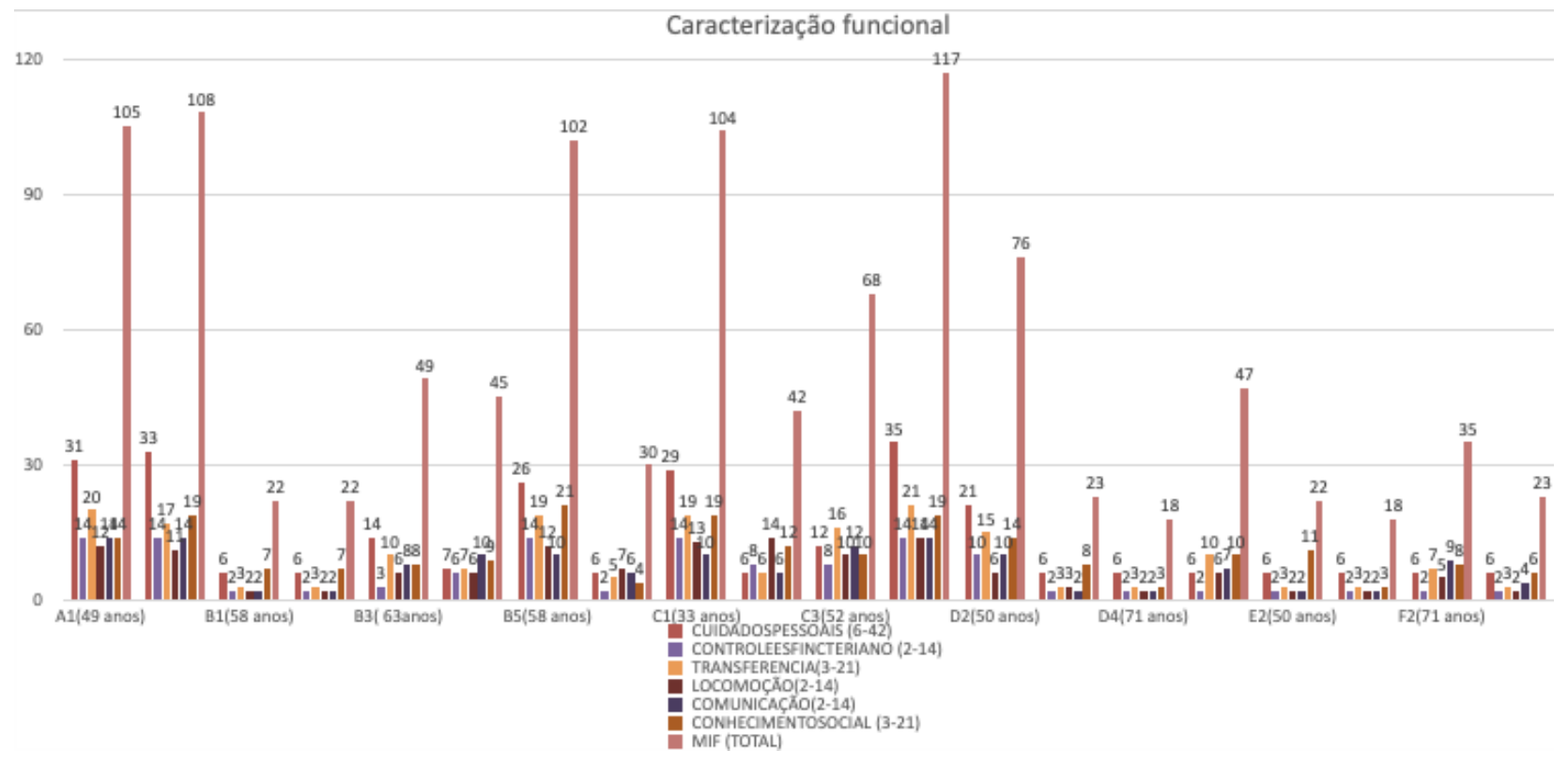

Fonte: Autores.

\section{Discussão}

O estudo teve como objetivo identificar a capacidade funcional de pessoas diagnosticadas com a Doença de Huntington (DH) em um município alagoano, através de uma série de casos. Além disso, identificou a idade relatada do aparecimento dos sintomas e caracterizou os grupos familiares analisados, assim como a condução do tratamento.

De acordo com a Secretaria Municipal de Saúde, existem vinte indivíduos diagnosticados com a DH e outros seis em investigação. O município tem uma população estimada de 25.206 habitantes (IBGE, 2020). Ao considerar o número de casos confirmados, há um registro de um caso para cada 1.260 habitantes. Essa alta prevalência de casos, relatada na literatura, é justificada pelo elevado número de casamentos consanguíneos e agravado pela demora na identificação dos casos, visto que os portadores da doença recebiam de forma equivocada o diagnóstico da doença de Parkinson (Heemskerk \& Roos, 2010). Os participantes desta pesquisa apresentaram parentesco dentro dos grupos construídos para a didática da compreensão dos resultados, contudo, até a realização da coleta de dados deste estudo, os mesmos afirmaram não terem sido submetidos a estudos genéticos, sendo este o caminho para entender a patogênese da doença, a partir de investigação molecular, não apenas epidemiológica.

Não existem dados sobre a real prevalência da DH no Brasil, como citado por Chemale (2000). Porém, o município de Ervália, na zona da mata do estado de Minas Gerais, com aproximadamente 18 mil habitantes, a prevalência mínima é de 7,2/10.000 habitantes, o que equivale a um número de 10,3 a 14,4 vezes maior que à prevalência mundial (Agostinho, 2015). Nos Estados Unidos a prevalência é de cerca de cinco a dez pessoas afetadas por 100 mil habitantes e essa prevalência é relativamente a mesma em todo o mundo, apesar do aumento em algumas regiões como Tasmânia e às margens do Lago Maracaibo na Venezuela, contudo, há diminuição de registros de casos em países como Japão, China, Finlândia e no continente africano (Chemale, 2000). Embora no Brasil não exista o registro exato dessas informações, a Associação Brasil Huntington (2005) estima que mil famílias sejam afetadas. Apesar da inexistência de estatísticas oficiais, estima-se que 13.000 a 19.000 são portadores do gene e 65.000 a 95.000 pessoas em risco (seus descendentes). Um estudo de revisão sistemática conduzido Baig, Strong e Quarrell (2016), que teve como objetivo identificar a prevalência de DH em quatro 
continentes, concluiu que a Europa apresenta o maior número de diagnósticos registrados, seguido pela América do Norte e Austrália, e reforça que o menor número de pessoas diagnosticadas está nos países asiáticos.

Em uma revisão da literatura, Pandey \& Rajamma (2018), relatam que a incidência da DH é variável em todo o mundo, como: Japão, África do Sul e Finlândia que apresentam taxas mais baixas da doença. Harper (1992) estudou a prevalência em países orientais e identificou 4 -10 por 100.000 pessoas em países ocidentais. No Reino Unido sugerem uma maior prevalência de DH no adulto, apresentando o valor de 12,3 por 100.000 com base em diagnósticos registrados (Evans et al., 2013). Há um alto registro de casos na Venezuela, causado por ambos os pais afetados e chegando a taxas superiores aos demais países, colaborando com o mapeamento e isolamento do gene responsável pela doença (Wexler et al., 2004).

Quanto aos resultados obtidos no questionário sociodemográfico, observa-se que grande parte dos acometidos tiveram os primeiros sintomas na fase mais produtiva da vida, a partir dos trinta anos de idade, contudo, a falta de informação sobre a doença influenciou o tempo entre os primeiros sintomas e o diagnóstico, interferindo na busca de atendimento médico especializado, consequentemente houve atraso no diagnóstico e tratamento, assim como o acesso às informações sobre a transmissão genética hereditária.

Os sintomas normalmente têm início na vida adulta, após os 30 anos, podendo ocorrer casos raros da forma juvenil, e apesentam sinais a partir de déficits motores (coreia, discinesia e distonia), sintomas psiquiátricos (depressão, ansiedade, distúrbios do sono) (Spires \& Hannan, 2007) e declínio cognitivo (dificuldade para se concentrar e acomodar informações recentes, declínio de habilidades linguísticas, discurso desorganizado e dificuldade na percepção). Com o avanço da doença, os déficits motores passam a ser predominantes, com a presença de rigidez e demência (Associação Brasil Huntington, 2016). $\mathrm{Na}$ forma juvenil, os sintomas são mais severos e são associados, em especial, à transmissão paterna de um alelo doente (Ximenes \& Teixeira, 2009).

A DH é uma doença autossômica dominante e, desta maneira, possui a chance de $50 \%$ de se desenvolver em um filho de portador e não tem relação com o sexo do indivíduo (Gil-Mohapel \& Rego, 2011). O padrão de transmissão familiar foi a primeira observação de cunho genético percebida na doença ainda no Século XIX, sendo identificada a mutação causadora apenas em 1993 (Martelli, 2014). Tal mutação é vista como uma expansão instável do tripleto citosina-adeninaguanina, na região codificante (Éxon 1) do gene IT15 que codifica a proteína huntingtina (Gil-Mohapel \& Rego, 2011). A ação da huntingtina não é consenso, mas quando mutada leva à formação de inclusões intracelulares, apoptose, mudanças no transporte celular e alterações de transcrição que acarretam lesões nos tecidos, principalmente nervoso, provocando atrofia dos núcleos da base da base (Martelli, 2014). A huntingtina mutante é expressa ao longo de toda a vida do indivíduo, mas na maior parte dos casos os sintomas só surgem na idade adulta, entre os 35 e 50 anos de idade. Cerca de $5 \%$ a $10 \%$ do total de casos se manifesta na forma juvenil da doença, chamada variante de Westphal, que acomete pacientes antes dos 20 anos de idade (Martelli, 2014). O diagnóstico é baseado na história familiar confirmada ou através de teste genético positivo (Mccolgan \& Tabrizi, 2018).

A doença se dá pela ocorrência de atrofia seletiva e progressiva do corpo estriado (compreende os núcleos caudado, putâmen e globo pálido) e do córtex cerebral, esta progressão é dividida em três estágios. No primeiro deles, o paciente apresenta mudanças discretas na coordenação motora, como movimentos involuntários, dificuldade para pensar e humor depressivo. No segundo estágio, a fala e a deglutição são afetadas e as habilidades de raciocínio lógico diminuem gradualmente. Já no terceiro e mais grave, a pessoa torna-se totalmente dependente, chegando até ao estado vegetativo (Silva et al., 2014). Os estudos mostram que déficits podem preceder os aparecimentos dos sintomas motores e diagnóstico formal da doença, havendo relatos de perdas discretas e déficit cognitivo até dez anos antes do diagnóstico (Wahlin et al., 2007). Com a evolução da doença o portador passa a relatar dependência completa para realizar as suas atividades de vida diária, 
assim como a necessidade de cuidados constantes e intensivos (Associação Brasil Huntington, 2016), sendo necessários incluí-los nos programas de intervenção (Silveira \& Silva, 2020).

$\mathrm{O}$ apoio de equipes multidisciplinares é necessário para garantir um cuidado integral aos portadores da Doença de Huntington, devendo ser acompanhados durante todos os ciclos da vida e na inserção dos cuidados paliativos, que deve acontecer o mais precoce possível, com apoio da assistência social, psicologia, fonoaudiologia, fisioterapia e da terapia ocupacional (Ramos et al., 2018).

Os aspectos físicos e cognitivos precisam ser trabalhados em todos os estágios da doença, onde o sujeito acometido apresenta uma desordem funcional, tendo um impacto negativo na qualidade de vida (Spitz, 2010). Embora cada indivíduo seja afetado de modo diferente, todos sofrem perda da capacidade funcional, tornando-se dependentes para realizar as Atividades Instrumentais da Vida Diária (AIVD), como cozinhar, arrumar a casa, telefonar, cuidar das finanças domésticas, e as Atividades da Vida Diária (AVD), ou seja, alimentar-se, vestir-se e cuidar da própria higiene. Essa perda de autonomia acontece principalmente em decorrência dos movimentos coreicos e das alterações cognitivas e comportamentais cada vez mais graves, levando à dependência completa (Associação Brasil Huntington, 2016).

As disfunções cognitivas estão associadas aos avanços da DH, contextualizadas aqui com alterações de memória e das funções executivas (atenção, cálculo, inibição, percepção, abstração), que se associam a desordens psiquiátricas como apatia, depressão, entre outros (Julayanont et al., 2020).

$\mathrm{O}$ cuidado aos pacientes com DH requer um esforço multidisciplinar, incluindo a participação e a atenção ao cuidador, mas prioritariamente é necessário haver participação de médicos geneticistas, neurologistas, psiquiatras, e, em algumas situações, o médico paliativista, além dos profissionais de reabilitação, terapeuta ocupacional, fonoaudiólogo, fisioterapeuta, dentista e psicólogo, assim como questões inerentes ao serviço social, que irão juntos traçar a intervenção pautada na qualidade de vida e funcionalidade do paciente e seus cuidadores, visto que não existe expectativa de cura para a doença (Wyant, Ridder \& Dayalu, 2017).

\section{Considerações Finais}

A alta prevalência de casos da Doença de Huntington no município de Feira Grande ainda é um fenômeno que requer investigação minuciosa sobre a origem e como vem se dando a transmissão genética ao longo dos anos. A partir dos dados coletados, foi possível identificar que, além do elevado número de casos, os participantes apresentaram perdas funcionais e dependências que demandam por cuidados domiciliares. Foi observado também que os portadores necessitam de maiores informações sobre a transmissão genética da doença, tendo em vista que 16 (92\%) dos participantes da pesquisa têm filhos.

Por se tratar de uma doença incapacitante, como demonstrado nos resultados deste estudo, faz-se necessário que haja um investimento em profissionais capacitados, como médicos especialistas, que possam conduzir adequadamente o tratamento farmacológico e orientações quanto a sua hereditariedade, assim como as equipes de reabilitação (terapeutas ocupacionais, fisioterapeutas, fonoaudiólogos e psicólogos), que são capazes de identificar barreiras e adequar o ambiente doméstico, favorecer o treino motor, cognitivo e potencializar aspectos relacionados à saúde mental, para que as atividades de vida diária sejam realizadas com independência, até quando possível, além de prestar apoio e assistência aos cuidadores, preservando assim a qualidade de vida dessas pessoas, visto que o diagnóstico da DH inclui a junção dos sintomas físicos, cognitivos e psiquiátricos que levam à dependência funcional.

É necessário que a gestão pública invista em dispositivos de saúde voltados para a reabilitação física e cognitiva, para que a assistência seja integral e favoreça mais qualidade de vida à população acometida. 
Por se tratar de um estudo transversal e descritivo, este estudo se limita a um recorte do quadro geral da população afetada no município investigado, os autores recomendam a necessidade da realização de estudos moleculares, assim como coortes que possam acompanhar as pessoas afetadas a partir do processo inicial dos sintomas e como se dá o seu percurso, tentando também modelos de intervenção e as suas respostas na qualidade de vida e evolução da doença.

\section{Referências}

Agostinho, L., da Silva, I., Maia, L. A., Azevedo, M., Faria, T. M., A., T. A., Pereira, S. P., Reis, R., Dos Santos, S. R., \& Paiva, C. L. (2015). A Study of a Geographical Cluster of Huntington's Disease in a Brazilian Town of Zona da Mata, Minas Gerais State. European neurology, 74(1-2), 62-68. https://doi.org/10.1159/000434630.

Alencar, A. et al. (2010) Prevalence of Huntington's disease in Feira Grande, a small city in Northeastern Brazil. Jornal de Neurologia, Neurocirurgia e Psiquiatria. 81(Supp11), A22.3-22. 10.1136/jnnp.2010.22638.5

Associação Brasil Huntington (2016). http://abh.org.br/perguntas-frequentes

Baig, S. S., Strong, M., \& Quarrell, O. W. (2016). The global prevalence of Huntington's disease: a systematic review and discussion. Neurodegenerative disease management, 6(4), 331-343. https://doi.org/10.2217/nmt-2016-0008.

Chemale, F. A., et al (2000). Doença de Huntington. Dissertação entregue para conclusão de curso na Disciplina de Genética e Evolução da Fundação Faculdade Federal de Ciências Médicas de Porto Alegre. Departamento de ciências Morfológicas, $37 \mathrm{fl}$.

Evans, S. J. W., et al. (2013).Prevalência da doença de Huntington em adultos no Reino Unido com base em diagnósticos registrados em registros de clínica geral. Journal of neurology, neurosurgery, and psychiatry, 84(10), 1156-60. 10.1136/jnnp-2012-304636.

Gil-Mohapel, J. \& Rego, A. C. (2011). Doença De Huntington. Rev Neurocienc, 19(4), 724-734.

Harper P. S. (1992). The epidemiology of Huntington's disease. Human genetics, 89(4), 365-376. https://doi.org/10.1007/BF00194305

Heemeskerk, A.W.; ROOS, R. (2010). Causas de morte na doença de Huntington. Journal of Neurology, Neurosurgery \& Psychiatry, 81 (22).

Instituto Brasileiro de Geografia e Estatistica (2020). População brasileira e unidades federativas. Acessos em 10 de fevereiro de 2020. Disponível: https://www.ibge.gov.br/apps/populacao/projecao/index.html.

Intrieri, A. C. U., et al. (2015). Huntington: distúrbio no cromossomo 4. Revista UNILUS Ensino e Pesquisa, 12(29), $22-34$.

Julayanont, P., Heilman, K. M., \& McFarland, N. R. (2020). Early-Motor Phenotype Relates to Neuropsychiatric and Cognitive Disorders in Huntington's Disease. Movement disorders : official journal of the Movement Disorder Society, 35(5), 781-788. https://doi.org/10.1002/mds.27980

Martelli, A. (2014). Aspectos clínicos e fisiopatológicos da Doença de Huntington. Archives of Health Investigation, 3(4), 32-39.

Mccolgan, P., \& Tabrizi, Sj. (2018) Doença de Huntington: uma revisão clínica. Eur J Neurol. 25(1), 24-34. doi:10.1111/ene.13413.

Pandey, M., \& Rajamma, U. (2018). Huntington's disease: the coming of age. Journal of genetics, 97(3), 649-664.

Ramos, N. O. et al. (2018). Doença neurodegenerativa rara: caracterização dos portadores de doença de huntington e ataxia espinocerebelar na Amazônia ocidental, Brasil. Rev. Saúde Pública, 1(2), 63-74.

Riberto, M. et al. (2004). Validação da versão brasileira da Medida de Independência Funcional. Acta Fisiatrica, 11(2), 72-6.

Silva, A. H. et al. (2014). Huntington: dificuldades enfrentadas pela família. Journal of the Health Sciences Institute, 32(2), 168-172.

Silveira, A. G., \& Silva, D. A. da. (2020). Burden of family members in caring for senile dementia patients: an integrative review. Research, Society and Development, $9(6)$, e179963671.

Spires, T. L. \& Hannan, A. j. (2007) . Molecular mechanisms mediating pathological plasticity in huntington's disease and alzheimer's disease. J Neurochem. 100(4), 874-882. 10.1111/j.1471-4159.2006.04275.x.

Spitz, M. et al. (2010). Doença de Huntington e outras coreias. Revista Hospital Universitário Pedro Ernesto, 9(1), 29-38.

Wahlin, R., Ludin, A. \& Dear K. (2007). Déficits cognitivos iniciais em portadores do gene sueco da doença de Huntington. Neuropsychology. 21(1), 31-44. doi:10.1037/0894-4105.21.1.31.

Wexler, N. S. et al. (2004). Família venezuelana revela que fatores genéticos e ambientais modulam a idade de início da doença de Huntington. Proceedings of the National Academy of Sciences of the United States of America, 101(10), 3498-503. doi:10.1073/pnas.0308679101.

Wyant, K. J., Ridder, A. J. \& Dayalu, P. (2017). Huntington's Disease-Update on Treatments. Current neurology and neuroscience reports, 17(4), 33. https://doi.org/10.1007/s11910-017-0739-9.

Ximenes, B. A. A. \& Teixeira, E. H. (2009). Doença de Huntington: aspectos diagnósticos e implicações éticas. Revista Ciência Médica. 18(5), $287-291$. 